\title{
A Suite of Receptor-Like Kinases and a Putative Mechano-Sensitive Channel Are Involved in Autoimmunity and Plasma Membrane-Based Defenses in Arabidopsis
}

\author{
Zhongqin Zhang, Chika Tateda, Shang-Chuan Jiang, Jay Shrestha, Joanna Jelenska, \\ DeQuantarius J. Speed, and Jean T. Greenberg
}

Department of Molecular Genetics and Cell Biology, The University of Chicago

Accepted 2 January 2017.

In plants, cell surface pattern recognition receptors (PRRs) provide a first line of defense against pathogens. Although each PRR recognizes a specific ligand, they share common signaling outputs, such as callose and other cell wall-based defenses. Several PRRs are also important for callose induction in response to the defense signal salicylic acid (SA). The extent to which common components are needed for PRR signaling outputs is not known. The gain-of-function Arabidopsis mutant of ACCELERATED CELL DEATH6 (ACD6) acd6-1 shows constitutive callose production that partially depends on PRRs. ACD6-1 (and ACD6) forms complexes with the PRR FLAGELLIN SENSING2, and ACD6 is needed for responses to several PRR ligands. Thus, ACD6-1 could serve as a probe to identify additional proteins important for PRRmediated signaling. Candidate signaling proteins (CSPs), identified in our proteomic screen after immunoprecipitation of hemagglutinin (HA)-tagged ACD6-1, include several subfamilies of receptorlike kinase (RLK) proteins and a MECHANO-SENSITIVE

\section{Z. Zhang, C. Tateda, and S.-C. Jiang contributed equally.}

Sequence data is available fromn the EMBL/GenBank data libraries under accession numbers At5g46330 (FLS2), At4g33430 (BAK1), At4g14400 (ACD6), At5g20480 (EFR), At3g21630 (CERK1), At2g14610 (PRI), At3g45640 (MPK3), At2g43790 (MPKO), At3g24240 (RGFR1/RGII), At1g34420 (RKI3), Atlg51790 (RKI2), At4g00340 (RLK4), Atlg53470 (MSL4), At4g23210 (CRK13), At4g04510 (CRK38), At4g21410 (CRK29), At4g39080 (VHA_A3) and At5g57110 (ACA8). Accession numbers for T-DNA lines are SALK_141277 (fls2), SALK_116202 (bakl-4), SALK_044334 (efr), 096F09 (cerk1-2), SALK_151594 (mpk3), SALK_040393 (rgfrl-1/rgil-2), SALK_020659 (rgil1), SALK_025281 (rki2-2), SALK_109214C (rki3), SALK_116983C (rlk4), SALK_142497 (msl4-1), SALK_013552 (msl4-2), SALK_085128C (crk13-1), SALK_035910 (crk38), SALK_008950 (crk29-1), SALK_111384 (crk29-2), SALK_119654 (vha_a3), and SALK_108260C (aca8-1).

Current address for Z. Zhang: Hebei Sub-center of Chinese National Maize Improvement Center, North China Key Laboratory for Crop Germplasm Resources of Education Minestry, College of Agronomy, Agricultural University of Hebei, Baoding, 007100 China.

Current address for C. Tateda: Iwate Biological Research Center, 22-174-4 Narita, Kitakami, Iwate 024-0003, Japan.

Corresponding author: Jean T. Greenberg; E-mail: jgreenbe @ uchicago.edu; Telephone: +1.773 .834 .1908 (office).

*The $\boldsymbol{e}$-Xtra logo stands for "electronic extra" and indicates that five supplementary figures and five supplementary tables are published online.

@ 2017 The American Phytopathological Society
CHANNEL OF SMALL CONDUCTANCE-LIKE 4 (MSL4). In acd6-1, CSPs contribute to autoimmunity. In wild type, CSPs are needed for defense against bacteria and callose responses to two or more microbial-derived patterns and an SA agonist. CSPs may function to either i) promote the assembly of signaling complexes, ii) regulate the output of known PRRs, or both.

Plasma membrane (PM) proteins work as key components of plant defense mechanisms. In Arabidopsis, one of the regulatory defense membrane proteins is ACCELERATED CELL DEATH 6 (ACD6), a multipass integral membrane protein that localizes to the endoplasmic reticulum (ER) and PM (Lu et al. 2005; Z. Zhang et al. 2014). ACD6-1, a single amino acid substitution (L591F) of ACD6, causes a constitutive autoimmunity phenotype, including high levels of the defense signal molecule salicylic acid (SA), reduced stature, small cell-death patches, ectopic mitogen-activated protein kinase (MAPK or MPK) activation, increased callose accumulation, and enhanced resistance to pathogens (Lu et al. 2003, 2005; Rate et al. 1999; Vanacker et al. 2001; Z. Zhang et al. 2014). Reducing SA accumulation in $a c d 6-1$ by introducing a mutation in a SA biosynthesis gene can completely suppress some acd6-1conferred phenotypes but only partially affects some defenserelated markers (Lu et al. 2009; Tateda et al. 2014). This indicates that there are SA-dependent and SA-independent components to the immunity phenotypes of acd6-1. Plants lacking ACD6 are more susceptible to Pseudomonas syringae and show delayed SA accumulation upon infection (Lu et al. 2003; Tateda et al. 2014).

Another class of important membrane proteins contains the pattern recognition receptors (PRRs) that initiate plant defense signaling upon binding to pathogen-associated molecular patterns (PAMPs) on the cell surface (Couto and Zipfel 2016). Arabidopsis PRRs include FLAGELLIN SENSING2 (FLS2), which binds flg22, a peptide derived from bacterial flagellin (Chinchilla et al. 2006; Gómez-Gómez and Boller 2000), and lysin-motif (LysM) domain proteins (LYM1, LYM3, CHITIN ELICITOR RECEPTOR KINASE, CERK1 and LYSINE MOTIF RECEPTOR KINASE5, LYK5) that bind fungal chitin or bacterial peptidoglycan (Cao et al. 2014; Miya et al. 2007; Petutschnig et al. 2010; Willmann et al. 2011), respectively. PRRs also associate with a few membrane proteins important for their respective activities. For example, BRI1-ASSOCIATED KINASE 1 (BAK1) rapidly makes a complex with FLS2 upon flg22 perception (Chinchilla et al. 2007; Heese et al. 2007). ARABIDOPSIS-AUTOINHIBITED $\mathrm{Ca}^{2+}$-ATPase (ACA8) and L-type lectin receptor kinase-VI.2 are also required for flg22-primed defenses, because of their association with FLS2 (Frei dit Frey et al. 2012; Huang et al. 2014; Singh et al. 2012). 
PRRs and ACD6 are linked in a regulatory network (Tateda et al. 2014; Z. Zhang et al. 2014). Perception of a PAMP in wildtype plants results in similar signaling outputs as acd6-1conferred autoimmunity phenotypes. These include activation of MAPKs, transcriptional reprogramming, and callose deposition to strengthen cell walls (Boller and Felix 2009; Schwessinger et al. 2011). Loss of FLS2 or BAK1 partially suppresses some acd6-1-conferred autoimmunity phenotypes, indicating that these PRRs contribute to signaling, even in the absence of PAMPs (Tateda et al. 2014). ACD6 also regulates the levels of FLS2, CERK1, and BAK1. In plants lacking ACD6 (acd6-2), receptor levels are reduced, resulting in attenuated responses to flg22 and chitin (Tateda et al. 2014).

The PRR/ACD6 regulatory network also includes SA. Treatment with the SA agonist benzo (1, 2, and 3) thiadiazole-7-carbothioic acid (BTH) elicits a PRR- and ACD6-dependent increase in callose deposition (Tateda et al. 2014). SA also acts both upstream and downstream of PRRs. Specifically, increased SA levels lead to upregulation of PRRs, whereas PAMP treatment can lead to SA accumulation (Mishina and Zeier 2007; Tsuda et al. 2008). In the case of FLS2 and BAK1, increased SA signaling (due to BTH treatment or $a c d 6-1$ ) causes enrichment of these proteins at the PM in an ACD6-dependent manner (Z. Zhang et al. 2014).

The ACD6 protein has two domains, a C-terminal multipass transmembrane domain and a $\mathrm{N}$-terminal cytosolic ankyrin (ANK) repeat domain (Lu et al. 2005; Z. Zhang et al. 2014). Many ANK domain proteins participate in protein-protein interactions and act as a scaffold for molecular interactions (Mosavi et al. 2004). ACD6 makes large protein complexes that include FLS2, CERK1, and BAK1 (Tateda et al. 2014; Z. Zhang et al. 2014). This raises the possibility that ACD6 works with other proteins to regulate defenses. ACD6-1 functions similarly to ACD6, however, ACD6-1 accumulates to higher levels, especially at the PM (Z. Zhang et al. 2014). For example, wild-type plants with extra genomic copies of ACD6 show a phenotype similar to acd6-1, albeit less dramatic (increased SA, defenserelated gene expression and disease resistance, activation of MAPKs, or spontaneous cell death, singly or in combination) (Lu et al. 2003, 2005; Z. Zhang et al. 2014). Both ACD6 and ACD6-1 have similar membrane topologies (Z. Zhang et al. 2014); the mutation in acd6-1 is within the transmembrane domain (Lu et al. 2003). Additionally, both proteins form similarly sized large membrane complexes (Z. Zhang et al. 2014). Finally, the composition of ACD6 and ACD6-1 complexes so far characterized is the same (Z. Zhang et al. 2014).

Since ACD6 is important for responses to PAMPs and BTH (Lu et al. 2003; Tateda et al. 2014), we reasoned that proteins associated with ACD6 may also be important for these responses. Because the abundance of ACD6 is relatively low compared with ACD6-1 in the membrane, we used ACD6-1 as a useful biological resource to biochemically identify unknown defense-related proteins, which we refer to as candidate signaling proteins (CSPs). The CSPs include several types of receptor-like kinase (RLK) proteins, MECHANOSENSITIVE CHANNEL OF SMALL CONDUCTANCE-LIKE 4 (MSL4) and ACA8, and more. We show that CSPs fit the criteria for being core basal immune components, as they are needed for responses to multiple stimuli, including two or more PAMPs and BTH.

\section{RESULTS}

\section{Identification of CSPs.}

To identify CSPs, we performed liquid chromatographytandem mass spectrometry (LC-MS/MS) on sodium dodecyl sulfate-polyacrylamide gel electrophoresis (SDS-PAGE) bands enriched during immunoprecipitation (IP) of functional hemagglutinin (HA)-tagged ACD6-1 (ACD6-1-HA) (Lu et al. 2005) from the microsomal fraction of extracts made from ACD6-1HA-expressing plants (Fig. 1A). The bands that were repeatedly seen as enriched in the ACD6-1-HA IP lane but not the control (Col) IP are indicated in Figure 1A. The same IP samples were used previously to identify peptides derived from FLS2 (Z. Zhang et al. 2014). Figure 1B shows that ACD6-1-HA protein was recovered using the high affinity HA matrix for affinity purification. Supplementary Table S1 describes proteins from which peptides were recovered at least twice. Some of the peptides recovered were derived from ACA8, a membrane protein known to be involved in PAMP signaling (Frei dit Frey et al. 2012). The CSPs selected for further characterization are known or predicted PM proteins (Tanz et al. 2013) annotated as several subfamilies of RLKs (Shiu et al. 2004) and MSL4 proteins (Table 1) but whose involvement in PAMP responses was not previously shown. RLKs identified include leucine-rich repeat (LRR) type, Sdomain type, and DUF26/cysteine-rich type RLKs (Table 1). One CSP (RGI1/RGFR1) was previously shown to bind to the root growth-promoting peptide RGF1 and contribute to root meristem growth (Ou et al. 2016; Shinohara et al. 2016).
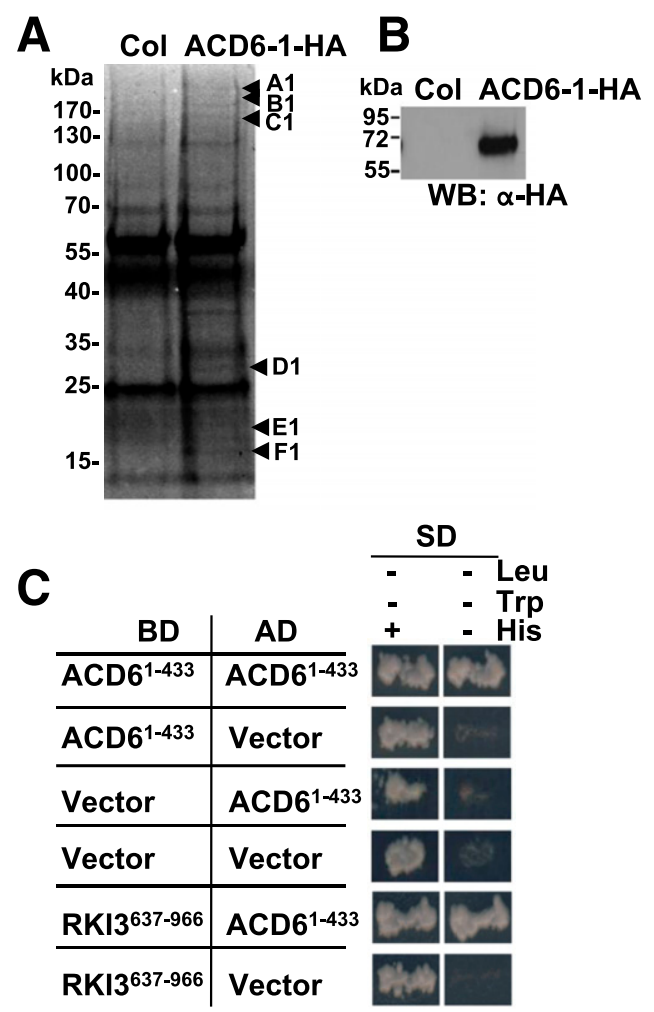

Fig. 1. Identification of candidate signaling proteins (CSPs). A, Proteins that coimmunoprecipitated with hemagglutinin (HA)-tagged ACD6-1 (ACD6-1-HA). Microsomal fraction proteins isolated from leaves of wildtype (Col) or transgenic plants expressing functional ACD6-1-HA. Possible ACD6-1-HA-interacting proteins were purified with $\alpha$-HA high-affinity matrix and were separated on sodium dodecyl sulfate-polyacrylamide gel electrophoresis. Bands were visualized by Coomassie blue staining. Differential bands (arrows A1 to F1) were cut and analyzed by liquid chromatography-tandem mass spectrometry. In a duplicate experiment, we analyzed peptides from three of the six bands. B, Immunoblot analysis using $\alpha$-HA antibody in immunoprecipitation samples shown in A. C, Yeast two-hybrid assays to detect interactions with the cytoplasmic domain of ACD6. ACD6 ${ }^{1-433}$ (ACD6 ANK) interacts with itself and the predicted cytoplasmic domain of RKI3. Photos show an example of yeast growth after 3 days; growth on -Leu/-Trp/-His synthetic defined (SD) medium indicates interaction. Replica plating was used to monitor growth on the different types of media. This experiment was repeated three times with similar results. 
We used a yeast two-hybrid mating assay and employed replica plating to test for direct interactions of the ANK domain of ACD6 (ACD6 ANK) and the predicted soluble and cytoplasmic portions of some of the CSPs found in the proteomic analysis. Figure 1C shows that ACD6 ANK interacted with the cytoplasmic (kinase) domain of RKI3 (RLK AND IMMUNITY 3), indicating that these proteins may bind to each other through their cytoplasmic domains. ACD6 ANK also interacted with itself (Fig. 1C) but failed to indicate positive interactions with other CSP domains tested (Supplementary Table S2). Furthermore, although FLS2 coimmunoprecipitates from plant extracts with both ACD6 and ACD6-1 proteins (Z. Zhang et al. 2014), two-hybrid interaction tests with the predicted cytosolic domain of FLS2 and ACD6 ANK were negative. We validated that some of the protein fusions (FLS2, ACD6 ANK, RKI3, and different MSL4 fragments) were expressed in yeast (Supplementary Fig. S1). However, since we could not detect some proteins, the negative results should be interpreted with caution. Additionally, it is possible that some CSPs and ACD6 might interact through their membrane or extracellular domains or might require accessory proteins for complex formation.

\section{CSPs contribute to basal defense.}

Since CSPs are predicted PM proteins, they might affect cell wall-based defense to protect plants against pathogens. We sought to test the role of individual CSPs by studying single $c s p$ T-DNA mutants from the SALK mutant collection. Most of these T-DNA mutants were already characterized in other studies, but a few have not been previously characterized, as indicated in Supplementary Table S3. When possible, we used two alleles of csp mutations to increase our confidence that the $\operatorname{csp}$ mutations are causal to the phenotype assayed. For single mutants not previously studied, we assayed the CSP transcript levels and found that they were reduced or undetectable (Supplementary Fig. S2A). In cases in which only one csp allele was available at the start of our study or in which the allele was not previously well-characterized, we analyzed T-DNA segregation patterns and validated that most lines had only one T-DNA insertion. Exceptions were lines with mutations in rki3 and $c r k 38$, which likely had more than one T-DNA insertion segregating (Supplementary Table S4). We included data from crk38 and rki3 below because they are in agreement with results from other csp mutants.
To test whether each CSP has a role in suppressing bacterial growth, we assayed csp mutants for their ability to support colonization by type III secretion-deficient Pseudomonas syringae pv. maculicola ES4326 hrc $\mathrm{C}^{-}$. Such bacteria lack secretion of effectors that might target RLKs or other defense proteins, making phenotypic analysis more tractable (Alfano and Collmer 1997; Belkhadir et al. 2012; Gimenez-Ibanez et al. 2009; Tsuda et al. 2008). Relative to wild type, all the $c s p$ mutants tested showed enhanced colonization by $P$. syringae pv. maculicola ES4326 $h r c C^{-}$, similar to the $f l s 2$ mutant (Fig. 2).

To further investigate the role of CSPs in basal defense, we tested whether they were important for the output pathways of PRRs. We assayed callose deposition in response to three PAMPs, namely, flg22, chitin, and elf18, a peptide derived from bacterial EF-Tu and recognized by the PRR EF-Tu receptor (EFR) (Zipfel et al. 2006). Flg22- or chitin-induced callose deposition was reduced in all of the $c s p$ mutants tested and the $a c a 8$ mutant (Fig. 3A and B). In contrast, only rki2-2 and crk13-1 showed reduced callose deposition in response to elf18 (Fig. $3 \mathrm{C})$. For the flg22 response, we also tested induction reactive oxygen species (ROS). None of the csp mutants were compromised for ROS induction (Supplementary Fig. S3).

Genevestigator (Hruz et al. 2008) shows that among all the CSPs, the transcripts of RKI2 and CRK13 were the most strongly induced by elf18 (Table 1), indicating that there might be a quantitative requirement for these CSPs during elf18-triggered signaling. Thus, all CSPs contribute to basal defense, but some have broader requirements (e.g., they are needed for all ligands or elicitors tested) and show strong ligand-induced signaling regulation.

Similar to treatment with PAMPs, SA or the SA agonist BTH also induce callose deposition in wild-type plants (Kohler et al. 2002; Tateda et al. 2014). Well-known PRRs and coreceptors FLS2, CERK1, EFR, and BAK1 are all required for maximum callose deposition in response to BTH (Tateda et al. 2014, 2015). We tested whether CSPs contribute to BTH-induced callose deposition, similar to PRRs. All of the single csp mutants had strong defects in BTH-induced callose deposition (Fig. 3D). We also tested the importance of ACA8, which associates with FLS2 (Frei dit Frey et al. 2012). Similar to csp mutants, the aca8-1 mutant showed less BTH-induced callose than wild type (Fig. 3D). These data indicate that CSPs, like ACA8 and

Table 1. Many candidate signaling proteins (CSPs) are induced by either microbial elicitors, the plant signal salicylic acid (SA), or both

\begin{tabular}{|c|c|c|c|c|c|c|c|}
\hline \multirow[b]{2}{*}{ AGI number } & \multirow[b]{2}{*}{ Name } & \multirow[b]{2}{*}{$\mathbf{R L K}^{\mathbf{a}}$} & \multicolumn{4}{|c|}{ Gene upregulated? } & \multirow[b]{2}{*}{ Predicted membrane? $^{c}$} \\
\hline & & & flg 22 & elf18 & chitin & SA & \\
\hline \multicolumn{8}{|c|}{ PAMP receptors } \\
\hline At5g46330 & FLS2 & LRR-XII & + & + & $\mathrm{N}$ & $\mathrm{N}$ & $\mathrm{Y}$ \\
\hline At5g20480 & EFR & LRR-XII & + & + & $\mathrm{N}$ & $\mathrm{N}$ & $\mathrm{Y}$ \\
\hline At3g21630 & CERK1 & LysM & ++ & + & $\mathrm{N}$ & + & $\mathrm{Y}$ \\
\hline \multicolumn{8}{|c|}{ Proteins involved in PAMP-triggered immunity signaling } \\
\hline At $4 \mathrm{~g} 33430$ & BAK1 & LRR-II & + & + & $\mathrm{N}$ & $\mathrm{N}$ & $\mathrm{Y}$ \\
\hline At5g57110 & ACA8 & & $\mathrm{N}$ & $\mathrm{N}$ & $\mathrm{N}$ & - & $\mathrm{Y}$ \\
\hline \multicolumn{8}{|l|}{ CSPs } \\
\hline At3g24240 & RGFR1/RGI1 & LRR-XI & $\mathrm{N}$ & $\mathrm{N}$ & $\mathrm{N}$ & $\mathrm{N}$ & $\mathrm{Y}$ \\
\hline Atlg51790 & RKI2 & LRR-1a & ++ & +++ & $\mathrm{N}$ & + & $\mathrm{Y}$ \\
\hline At1g34420 & RKI3 & LRR-X & + & + & $\mathrm{N}$ & + & $\mathrm{Y}$ \\
\hline At4g00340 & RLK4 & S-domain & $\mathrm{N}$ & $\mathrm{N}$ & $\mathrm{N}$ & $\mathrm{N}$ & $\mathrm{Y}$ \\
\hline At4g23210 & CRK13 & DUF26 & ++ & +++ & + & $\mathrm{N}$ & $\mathrm{Y}$ \\
\hline At4g04510 & CRK38 & DUF26 & ++ & + & $\mathrm{N}$ & $\mathrm{N}$ & $\mathrm{Y}$ \\
\hline At4g21410 & CRK29 & DUF26 & ++ & + & $\mathrm{N}$ & $\mathrm{N}$ & $\mathrm{Y}$ \\
\hline At1g53470 & MSL4 & & NA & NA & NA & NA & $\mathrm{Y}$ \\
\hline At4g 14400 & ACD6 & & $\mathrm{N}$ & +++ & $\mathrm{N}$ & +++ & $\mathrm{Y}$ \\
\hline
\end{tabular}

${ }^{a}$ Receptor-like kinase (RLK) subfamily (Shiu et al. 2004).

${ }^{\mathrm{b}} \mathrm{N}$, no change, + or,$->2.5$-fold change (up- or downregulation, respectively),,$++>5$-fold change (upregulation),,$+++>10$-fold change (upregulation), $P<$ 0.05 . NA = not available from Genevestigator (Hruz et al. 2008).

${ }^{c}$ Subcellular localization predictions were from the subcellular localization database for Arabidopsis proteins (SUBA3) (Tanz et al. 2013). Y indicates a predicted plasma membrane, from the SUB database. 
FLS2 (Frei dit Frey et al. 2012; Zipfel et al. 2004), are needed for basal immunity.

\section{CSPs contribute to acd6-1 autoimmunity.}

FLS2, BAK1, and CERK1 membrane protein levels are higher in acd6-1 than wild-type plants (Tateda et al. 2014). Thus, CSPs might also be present at elevated levels in acd6-1. Because antibody reagents for CSPs were not available, we used transcript accumulation as a proxy for CSP protein levels. This seemed reasonable, since the transcript level of FLS2 was elevated in acd6-1 compared with wild type (Fig. 4). We found that the transcript levels of the CSPS tested were also higher in acd6-1 than wild type (Fig. 4).

At least one CSP (CRK13) was reported to confer an autoimmunity phenotype when overexpressed (Acharya et al. 2007). This raised the possibility that the high levels of CSPs might contribute to the autoimmunity phenotype of acd6-1. The acd6-1 mutant has a small rosette size that can be quantitatively suppressed when a defense regulator is lost due to a mutation (Rate et al. 1999). Genetic analysis has shown that the rosette size of acd6-1 provides a sensitive indicator of a gene's involvement in defense responses, as even small changes in size correlate with reduced defense signaling (Lu et al. 2009; $\mathrm{Ng}$ et al. 2011; Song et al. 2004; Tateda et al. 2014; Wang et al. 2011).

To test whether CSPs contribute to the acd6-1 autoimmunity phenotype, we constructed homozygous double mutants between acd6-1 and T-DNA alleles of genes encoding some CSPs. CSP single mutants had normal rosette morphologies compared with wild type (Fig. 5A). Loss of CSPs partially rescued the acd6-1conferred small rosette phenotype (Fig. 5B).

In acd6-1, high SA levels are correlated with the small rosette phenotype ( $\mathrm{Lu}$ et al. 2003, 2009). Therefore, we measured SA levels and signaling in acd6-1 csp plants. High-performance liquid chromatography (HPLC) analysis showed that SA levels were modestly reduced in all the acd6-1 csp plants (Fig. 6A). Additionally, PR1 protein levels, transcripts of which are strongly dependent on SA accumulation in acd6-1 ( $\mathrm{Lu}$ et al. 2009; Rate et al. 1999), were reduced in the acd6-1 csp double mutants (Fig. 6B, Supplementary Fig. S4A). Single $c s p$ mutants had low basal PR1 transcript levels, similar to wild type (Supplementary Fig. S5A). We assessed additional autoimmunity phenotypes and found that all the acd6-1 csp double mutants showed quantitative reductions in MAPK activation, accumulation of
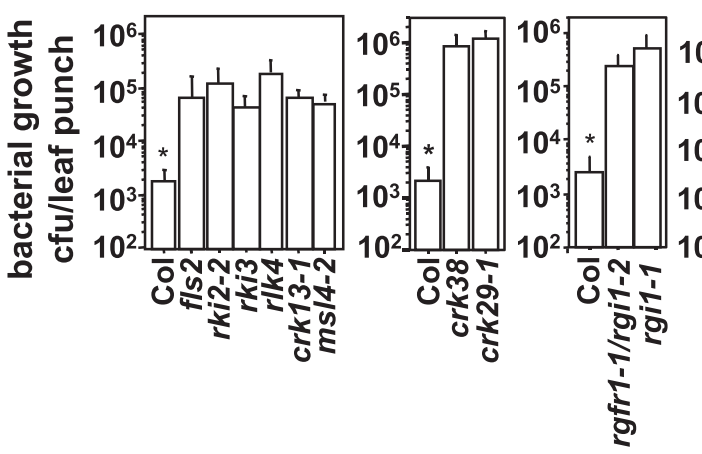

Fig. 2. Increased colonization of Pseudomonas syringae pv. maculicola ES4326 hrc $C^{-}$in loss-of-function $c s p$ mutants. The indicated mutants and wild type $(\mathrm{Col})$ were sprayed with $P$. syringae pv. maculicola ES4326 $h r c C^{-}$at a dose at an optical density at $600 \mathrm{~nm}$ of 0.03 and, three days later, bacteria were enumerated from eight leaf discs per genotype. Bars indicate standard deviations. Colonization of mutant plants was higher than that seen in wild-type $\mathrm{Col}$ (one asterisk [*] indicates $P<0.04$, Fishers least significant difference test, a posthoc test). Each mutant was independently tested three or more times with similar results.
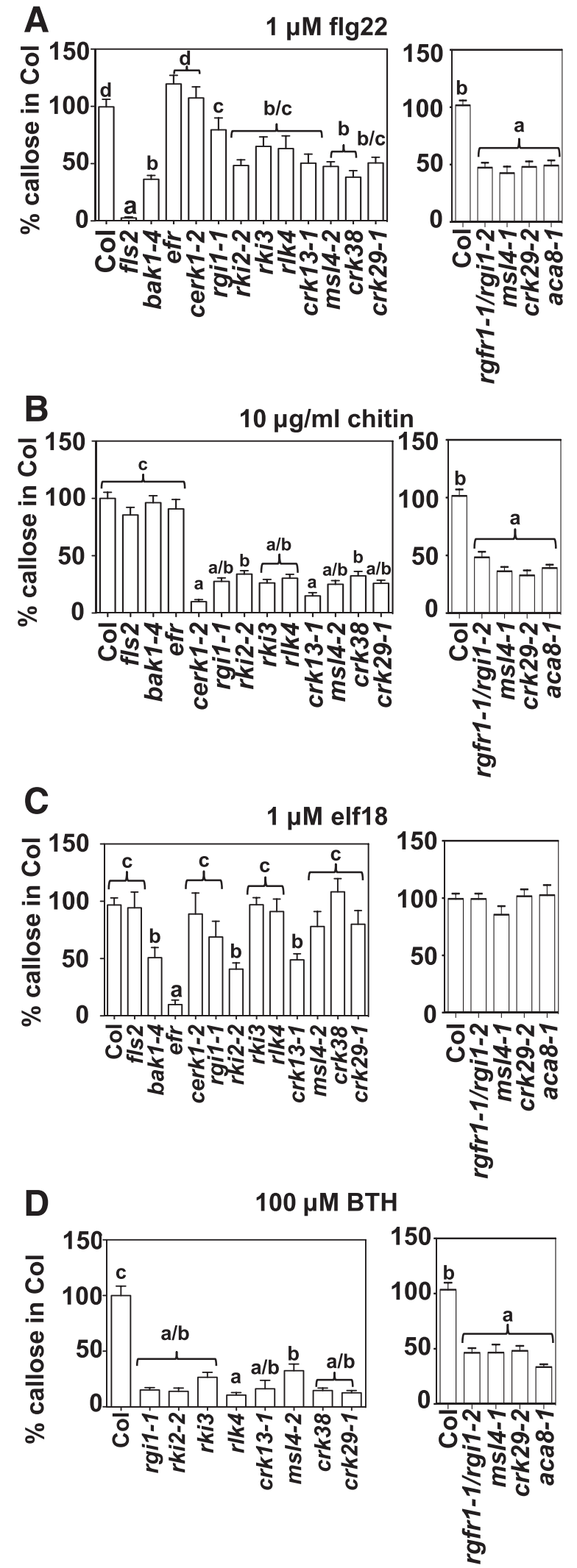

Fig. 3. Callose deposition in loss-of-function $c s p$ mutants in response to pathogen-associated molecular patterns and benzo (1,2, and 3$)$ thiadiazole7-carbothioic acid (BTH). A and $\mathbf{C}$, Callose deposits in leaves of indicated plants as percentage of callose in wild-type (Col) $18 \mathrm{~h}$ after $1 \mu \mathrm{M}$ flg 22 or $1 \mu \mathrm{M}$ elf18 infiltration, respectively, or $\mathbf{B}$ and $\mathbf{D}, 24 \mathrm{~h}$ after $10 \mu \mathrm{g} / \mathrm{ml}$ chitin or $100 \mu \mathrm{M}$ BTH infiltration, respectively. Callose was visualized by aniline blue staining. Bars show standard error of three independent experiments analyzed together $(n>24)$. Letters above bars indicate significance groups as determined by the Newman-Keuls multiple comparison test, $P<0.05$. 
At1g51890 transcripts (a marker for PRR-mediated signaling (He et al. 2006), callose deposition, and ectopic spontaneous cell death (Fig. 6C to F).

In our analysis of the acd6-1 csp double mutants, all the mutations that partially suppressed acd6- 1 had T-DNA insertions that affected the size and extent of callose deposition in acd6-1. Therefore, as a control that a T-DNA insertion itself does not cause these phenotypes, we constructed a double mutant between acd6-1 and vha_a3, another T-DNA mutant. We chose vha- $a 3$ because we recovered peptides from VHA_A3 in one of the two proteomic trials (TLQLVLLFLALVSVPCMLLPKPFI LK, TLQLVLLFLALVSVPCMLLPKPFILKK). The acd6-1 $v h a \_a 3$ plants were morphologically very similar to $a c d 6-1$ and showed no suppression of callose (Figs. 5B and 6E). Thus, the T-DNA itself is not responsible for the suppression acd6-1conferred phenotypes.

We also tested the role of MAPK signaling through MPK3 in acd6-1. Interestingly, loss of MPK3 partially suppressed several acd6-1 phenotypes, confirming that MPK3 actively signals in acd6-1 (Fig. 6D-F). However, the PRI transcript levels in acd6-1 $m p k 3$ and acd6-1 plants were similar, suggesting that MPK3 does not affect SA signaling in acd6-1. Thus, CSPs might regulate acd6-1-conferred autoimmunity phenotypes in two ways, either singly or together: i) by controlling SA accumulation or ii) through the activation of MAPK.

\section{DISCUSSION}

In this study, we used the defense regulatory protein ACD6-1 that is highly enriched at the PM (Z. Zhang et al. 2014) as a powerful biological resource to identify CSPs that might be involved in PM-based immunity. We found that CSPs include members of several RLK subfamilies and MSL4, which function in autoimmunity as well as in SA- and PAMP-response pathways. Thus, CSPs may participate in responses to multiple pathogens or defense-related stimuli, or both.
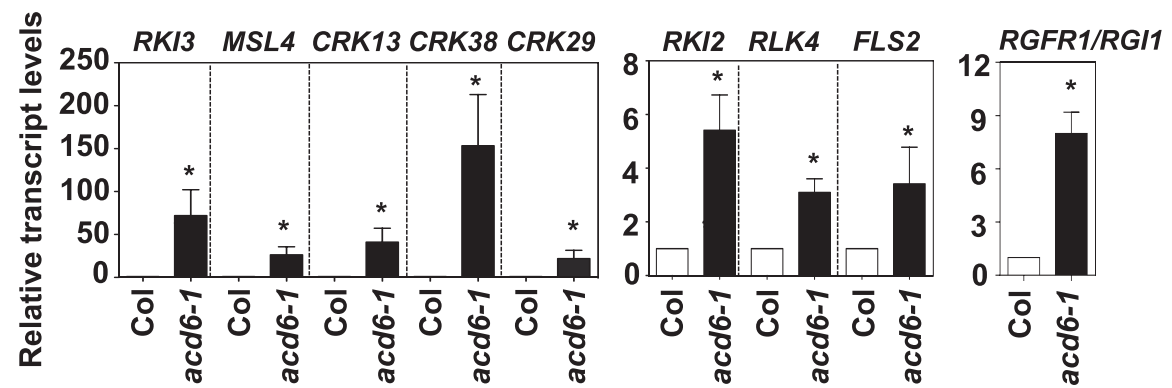

Fig. 4. Upregulation of transcript levels of candidate signaling protein genes (CSPs) in acd6-1. Transcript levels of CSPs in acd6-1 relative to CBP20 as determined by quantitative real time polymerase chain reaction $(n=3)$. Bars show standard error of three independent experiments analyzed together. Asterisk indicates significant difference from wild type $(\mathrm{Col}), P<0.05$, Student's $t$ test.
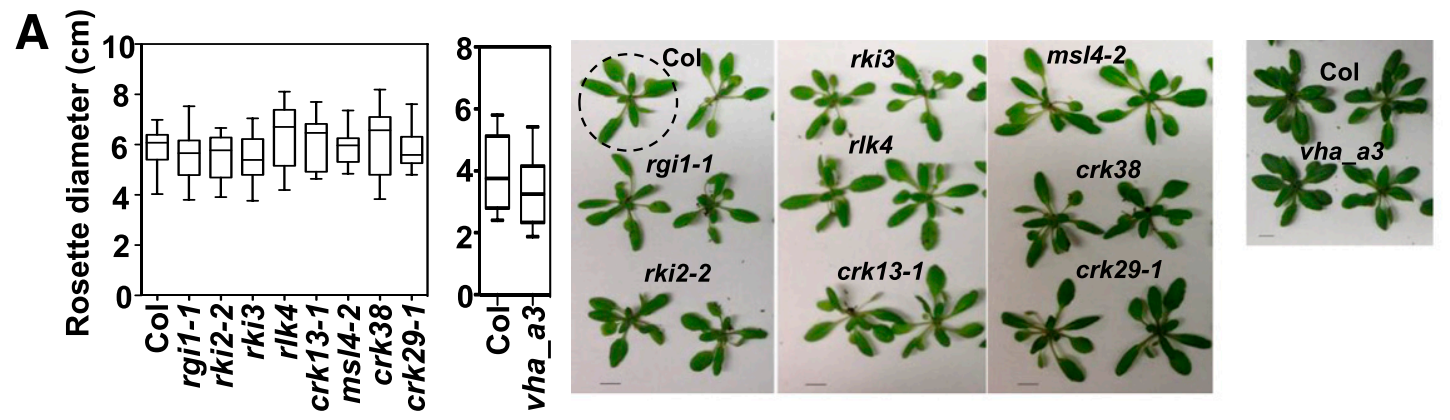

B
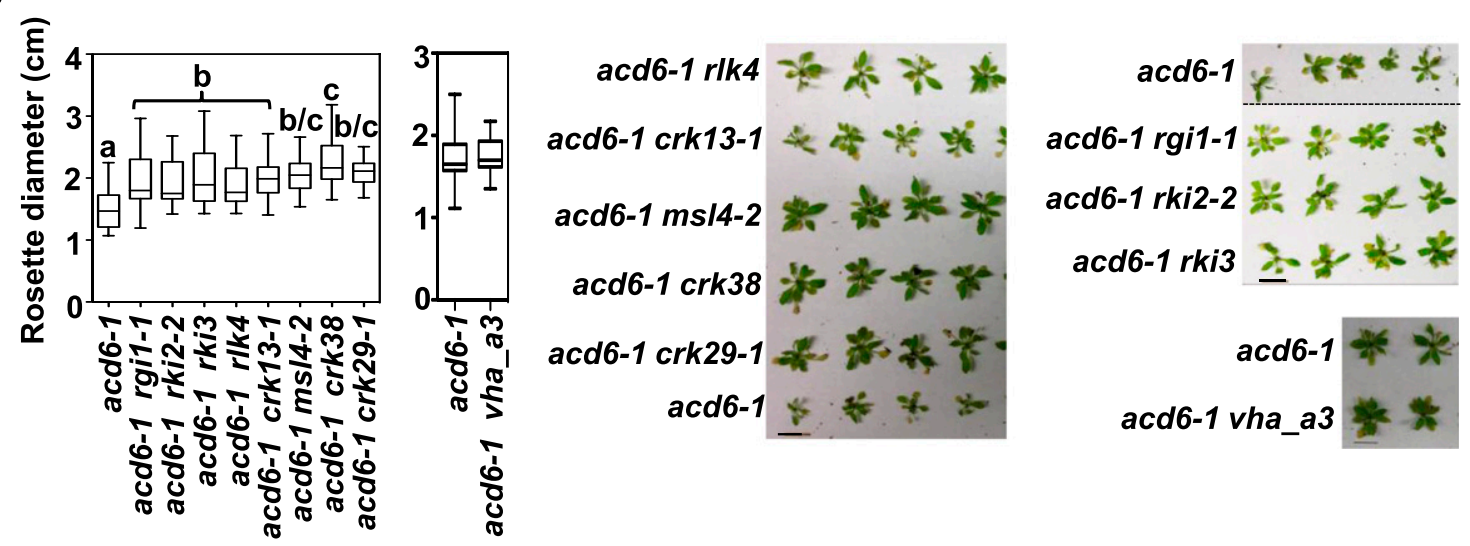

Fig. 5. Loss of individual candidate signaling proteins suppresses the acd6-1-conferred small rosette phenotype. A, Rosette diameters of $c s p$ mutants in wildtype or B, acd6-1 background. Bars show Whiskers (the full range of the data): Min to Max $(n>15)$. This experiment was repeated three or two (right panels in A and B, respectively) times with similar results. Letters above bars represent significance groups as determined by the Newman-Keuls multiple comparison test, $P<0.05$. Pictures show rosettes of wild-type $(\mathrm{Col})$ plants or the indicated mutants. Rosette sizes were estimated by measuring the diameter of circles. 
Like PRRs, CSPs may be regulated by ACD6. Membrane levels of FLS2, CERK1, and BAK1 are positively controlled by ACD6, as evidenced by their levels in loss- and gain-of-function mutants (Tateda et al. 2014, Z. Zhang et al. 2014). FLS2 and many CSP transcripts are up-regulated in acd6-1 plants. Previous analysis of ACD6- and ACD6-1-containing complexes showed that they are similar in size and composition; both ACD6 and ACD6-1 form complexes with FLS2 and several chaperones (Z. Zhang et al. 2014). A future goal will be determining whether CSPs also form specific complexes with the wild-type version of, one or more, ACD6, ACD6-1, or known ACD6-associated proteins. In support of this possibility, RKI3 can form complexes with the ANK domain of ACD6 (this study), and RGI1/RGFR1 was reported to form complexes with BAK1 in yeast two-hybrid assays (Ou et al. 2016). ACD6 and ACD6-1 are polytopic membrane proteins of very low abundance and are subject to ER quality control and degradation (Z. Zhang et al. 2014). As a consequence, these proteins do not tolerate fusions to large tags that are typically used for live imaging and interaction studies (e.g., green fluorescent protein [GFP], split GFP, split luciferase), which precludes the use of fluorescence microscopy and spectroscopy or luminescence-based methods for in planta validation
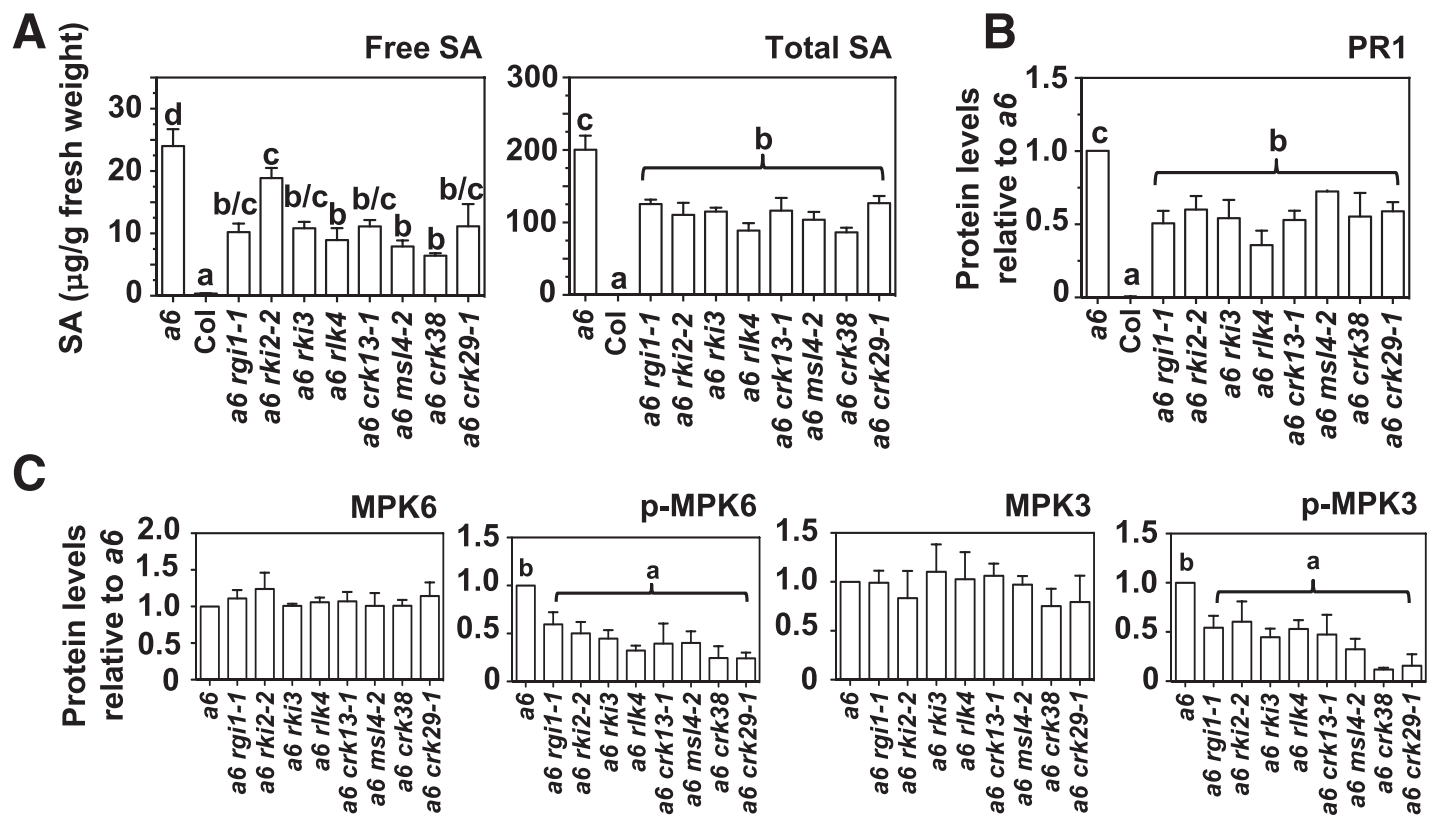

D
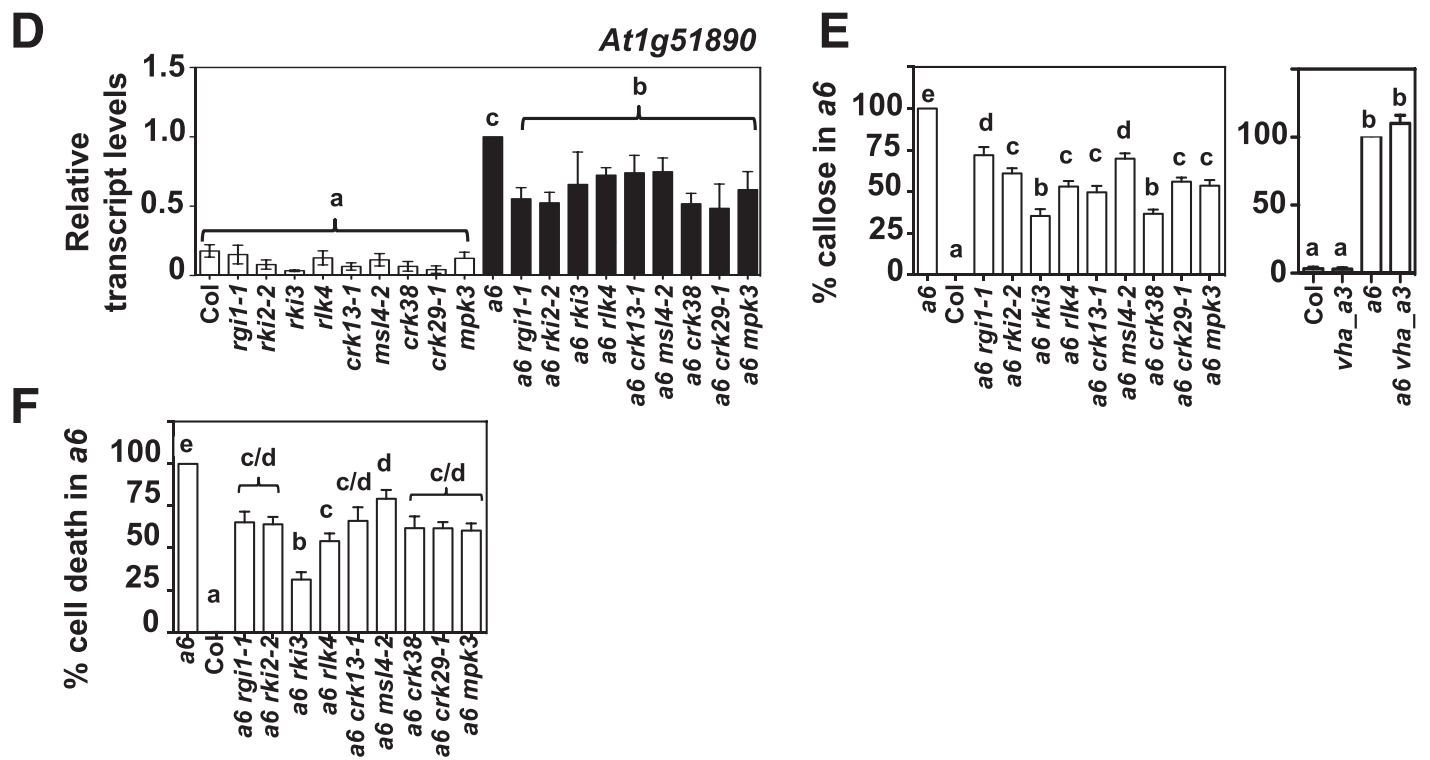

Fig. 6. Loss of individual candidate signaling proteins suppresses acd6-1-conferred autoimmunity phenotypes. A, Endogenous salicylic acid (SA) levels measured using high-performance liquid chromatography in the indicated plant lines $(n=6)$. This experiment was repeated twice with similar results. B, Graph shows PR1 protein levels obtained by immunoblot analysis in the acd6-1 csp double mutants, normalized relative to PR1 levels in acd6-1, using six biological replicates from two independent experiments analyzed together. C, Graphs show the mean fold change in total and mitogen-activated protein kinase (p-MPK3 or p-MPK6) levels (normalized to total protein) of the indicated plants relative to the level in acd6-1, quantified using immunoblot analysis from three independent experiments. D, Transcript levels of At1g51890 in the indicated plants, relative to CBP20, in $a c d 6-1$ and the indicated genotypes, determined by quantitative real time polymerase chain reaction from at least three experiments analyzed together. E, Callose deposits in leaves of indicated plants ( $n \geq 20$ per experiment; data from three experiments were analyzed together). F, Cell death in acd6-1 csp double mutants is shown as percentage of the area of cell death in acd6-1 $(n \geq 15)$. In different experiments, there was an 18 to $26 \%$ area of cell death per view field in acd6-1. Each genotype was tested in at least two independent experiments. Bars show standard error; $\mathrm{Col}$ and $a 6$ are wild type and $a c d 6-1$, respectively. Letters above bars represent significance groups as determined by the Newman-Keuls multiple comparison test, $P<0.05$. 
of complexes. Additionally, we have not succeeded in expressing functional ACD6 or ACD6-1 ectopically in Nicotiana benthamiana. Future evaluation of potential in planta complexes that involve ACD6/ACD6-1 and specific CSPs will require the development of new antibody reagents specific for the CSPs.

CSPs act in the same pathways as some PRRs to regulate callose deposition in response to multiple stimuli (e.g., flg22, chitin, and $\mathrm{BTH})$. We recently found that, in addition to their roles in the perception of specific PAMPs, FLS2 and CERK1 are needed for maximal responses to the SA agonist BTH (Tateda et al. 2014). The reduced responses of $c s p$ mutants might result from altered composition or function, or both, of ACD6-containing complexes, which normally contain FLS2, BAK1, and CERK1 (Tateda et al. 2014; Z. Zhang et al. 2014). It is interesting that ACA8, a known FLS2 interactor (Frei dit Frey et al. 2012), is needed for maximal callose induction in response to flg22, chitin, and BTH. Since ACA8 and CSPs were found in our proteomic screen after IP of ACD6-1-HA, it is possible that CSPs function together with ACA8 to regulate receptor functions.

How do CSPs function to regulate defenses? As discussed above, they all promote callose deposition in response to BTH, flg22, and chitin. However, only two $c s p$ mutants have reduced elf18-induced callose, indicating that there are some differences in the roles of CSPs. The high upregulation of the corresponding genes (RKI2 and CRK13) by elf18 treatment is reminiscent of the regulation and roles of the plant defense peptide Pep1 receptors PEPR1 and PEPR2 (Krol et al. 2010; Yamaguchi et al. 2010). Those two receptors are up-regulated in response to flg22 or elf 18 and are required for maximal responses to these PAMPs (Ma et al. 2012; Ross et al. 2014; Yamaguchi et al. 2010). Thus, RKI2 and CRK13 appear to be part of a signal amplification cycle associated with EFR-mediated signaling.

In contrast to the callose response, single CSPs are not required for the flg22-induced ROS burst. Recently, MPK3 was reported to be a negative regulator of flg 22 responses and its activation is not needed for the ROS burst (Frei dit Frey et al. 2014; $\mathrm{Xu}$ et al. 2014). Similar to CSPs, ACA8 is also needed for maximal callose induction in response to $\operatorname{flg} 22$ and for limiting bacterial growth but not for flg22-induced ROS (Frei dit Frey et al. 2012). However, in a double mutant of aca8 and aca10, ROS accumulation in response to flg22 is reduced (Frei dit Frey et al. 2012). Thus, it is possible that CSPs are involved in flg22 signaling independent of the ROS burst or multiple CSPs may act in a functionally redundant manner to regulate the ROS burst.

acd6-1 plants have multiple signaling events constitutively activated, which provides a sensitive background for studying quantitative effects on signaling networks (Lu et al. 2003; $\mathrm{Ng}$ et al. 2011). Loss of each CSP or FLS2 in acd6-1 results in similar attenuation of defense phenotypes, with the exception of an effect on the levels of MPK3 and MPK6 activation, which FLS2 does not impact (Tateda et al. 2014). Thus, CSPs may function in close proximity to FLS2 in the defense regulatory network while also having distinct regulatory functions. We do not know what causes MAPK activation in acd6-1, but one possibility is that having high CSP levels might be sufficient to activate MAPK signaling. Although MAPK activation was not directly tested, plants with ectopic expression of CRK13 or other CRKs (e.g., CRK4, CRK6, and CRK36) display defense phenotypes similar to acd6-1 (Acharya et al. 2007; Yeh et al. 2015). It is unlikely that SA accumulation is directly causal to MAPK activation in acd6-1, as treatment with an SA agonist is not sufficient to activate MAPKs in wild-type plants (Beckers et al. 2009).

CSPs might be required for one or more PAMP-stimulated signaling steps. ACD6 resides in large complexes and, together with SA, regulates PAMP receptor levels and localization on the PM (Tateda et al. 2014; Z. Zhang et al. 2014). Several types of
RLKs and MSL4 are involved in the ACD6/SA feedback loop and different ligand-induced responses. Some Arabidopsis accessions have high resistance to multiple pathogens due to activated natural alleles of ACD6 (Todesco et al. 2010). We speculate that the CSPs identified in this study contribute to the broadspectrum resistance conferred by these natural ACD6 alleles, which show phenotypes similar to acd6-1 (Todesco et al. 2010) in Arabidopsis. Furthermore, CSPs may be good candidates for use in generating broad-spectrum resistance to pathogens in crop species, either through genetic engineering of plants with higher levels of CSPs or screening breeding populations for individuals with naturally higher CSP levels.

\section{MATERIALS AND METHODS}

\section{Arabidopsis plants and growth conditions.}

All plants used in this study were derived from the Arabidopsis thaliana Columbia (Col-0) accession, referred to in this work as Col. Mutants and transgenic seeds used herein were previously described (acd6-1, fls2, bak1-4, efr-1, cerk1-2, mpk3, rgfr1-1/rgil-2, rgil-1, rki2-2, rlk4, crk13-1, crk29-2, msl4-1, aca8-1, and ACD6-1-HA) (Acharya et al. 2007; Araya et al. 2014; Danna et al. 2011; Hachez et al. 2011; Haswell et al. 2008; Heese et al. 2007; Lu et al. 2005; Miya et al. 2007; Ou et al. 2016; Rate et al. 1999; Shan et al. 2008; Shinohara et al. 2016; Wang et al. 2007; Yeh et al. 2015; J. Zhang et al. 2014; Zipfel et al. 2006) or were obtained from the Arabidopsis Biological Resource Center (Ohio State University) (Alonso et al. 2003) as T-DNA insertion lines (rki3, crk38, crk29-1, msl4-2, vha_a3). Homozygous lines were identified by PCR using gene-specific primers and the left border primer of the T-DNA (5'-ATTTTGCCGATTTCGGAA-3'). Double mutants with acd6-1 were obtained by doing crosses and screening the $\mathrm{F}_{2}$ generation for acd6-1 heterozygotes by polymerase chain reaction (PCR), using derived cleaved amplified polymorphic sequence markers (Rate et al. 1999) and appropriate primers to identify plants homozygous for the second mutation. $F_{3}$ generation plants were then used to identify plants homozygous for both acd6-1 and the second mutation. Plants were propagated for at least two generations after obtaining homozygous single or double mutants and were then grown as described (Butt et al. 1998; Greenberg et al. 1994), in 16-h light and 8-h dark conditions for 20 to 23 days, and were harvested for various assays.

We confirmed that most of the T-DNA lines contained a single insertion by analyzing the segregation pattern of all T-DNAs in the $\mathrm{F}_{2}$ generation of each cross with acd6-1. We used left borderspecific primers (Fw; 5'-CTATCAGGGCGATGGCCCACTACG TGAACCAT-3', Rv; 5'-CCGAGCTCGAATTTCCCCGATCG-3') to detect the ratio of plants without or with T-DNA insertions. We confirmed, in each case, that the correct cross was analyzed by using gene-specific primers for each line and the left border primer of the T-DNA.

\section{Isolation of total and membrane proteins and IP.}

Total and membrane protein isolation in plant was performed at $4^{\circ} \mathrm{C}$, as previously described (Tateda et al. 2014), with some modifications. To get the crude (total) extracts, $10 \mathrm{~g}$ of leaf tissue was homogenized with $30 \mathrm{ml}$ of grinding buffer A ( $50 \mathrm{mM}$ Tris$\mathrm{HCl}, \mathrm{pH} 7.5,0.33 \mathrm{M}$ sucrose, $5 \mathrm{mM}$ EDTA, $150 \mathrm{mM} \mathrm{NaCl}$, and protease inhibitor cocktail; Roche, Mannheim, Germany). After centrifugation at $10,000 \times g$ for $10 \mathrm{~min}$ to remove the insoluble material, the supernatant was further centrifuged at $100,000 \times g$ for $60 \mathrm{~min}$ to pellet membrane and soluble fractions. The microsomal membrane protein was resuspended with $1 \mathrm{ml}$ of buffer B (50 mM Tris- $\mathrm{HCl}, \mathrm{pH} 7.5,10 \%$ glycerol, $0.5 \%$ Triton X-100, protease inhibitor cocktail). For IP assays with anti-HA antibody, solubilized microsomal membranes were incubated with antiHA matrix (Roche) overnight at $4^{\circ} \mathrm{C}$ with gentle shaking. The 
eluted proteins were separated by 4 to $20 \%$ Precise protein gels (Thermo Scientific, Rockford, IL, U.S.A.) and stained by Imperial protein stain (Thermo Scientific). Bands present specifically in ACD6-1-HA were cut, were digested with trypsin, and were analyzed by LC-MS/MS (Jelenska et al. 2010).

For MPK and phospho-MPK, total protein extract was prepared from $0.5 \mathrm{~g}$ of leaf tissue in $1 \mathrm{ml}$ of grinding buffer $\mathrm{A}$ as described above.

To extract PR1 protein, leaf tissue ground into fine powder in liquid nitrogen was suspended in $1.22 \mu \mathrm{l}$ of $2.22 \times$ denaturing sample buffer (125 mM Tris-HCl, pH 6.8, 20\% glycerol, 4\% SDS, $5 \mathrm{M}$ Urea, $0.01 \%$ bromophenol blue, $0.22 \mathrm{M}$ dithiothreitol) per milligram of tissue and was incubated at $50^{\circ} \mathrm{C}$ for $15 \mathrm{~min}$, then $94^{\circ} \mathrm{C}$ for $5 \mathrm{~min}$. Supernatants of the extracts were obtained after centrifugation at $12,000 \times g$.

The protein extraction of transformed yeast strains was performed as described in the yeast protocols handbook (Clontech, Mountain View, CA, U.S.A.).

\section{Immunoblotting analysis.}

Proteins from plant or yeast extracts were separated by SDSPAGE. Primary antibodies used for immunoblots were shown as follows: anti-HA antibody (mouse, 16B12, 1:1,000; Covance, Berkeley, CA, U.S.A.), anticMyc antibody (mouse, 9E11, 1:1,000; Covance), anti-PR1 antibody (rabbit, AS10 687, 1:2,500; Agrisera, Vännäs, Sweden), anti-MPK3 (rabbit, M 8318, 1:3,000; Sigma, Saint Louis), anti-MPK6 (rabbit, A 7104, 1:3,000; Sigma), and antiphospho-p44/42 MAPK (Erk1/2) (Thr202/Tyr204) (rabbit, 4370, 1:1,000; Cell Signaling Technologies, Danvers, MA, U.S.A.). Secondary horseradish peroxidase conjugated antimouse and antirabbit antibody (Thermo Scientific) were used at 1:1,000. SuperSignal West pico stable peroxidase (Thermo Scientific) or SuperSignal West Femto stable peroxidase (Thermo Scientific) were used to detect immunoblot signals.

\section{Quantitation of immunoblots.}

PR1 levels were quantified by densitometry using Quantity One software (Bio-Rad, Hercules, CA, U.S.A.) and were normalized relative to the total protein content on duplicate Coomassiestained gels. For MPK3, MPK6, and phospho-MPK3/6, quantitation of immunoblot membranes were conducted as described (Tateda et al. 2014).

\section{Database searching of peptides identified by LC-MS/MS.}

LC-MS/MS protein identification was performed at Chicago Biomedical Consortium as in (Jelenska et al. 2010).

Database searching. All MS/MS samples were analyzed using Mascot (Matrix Science, London) and Sequest (ThermoFinnigan, San Jose, CA, U.S.A.). The ipi.ARATH.v3.43 database (36853 entries) was searched assuming trypsin digestion. Mascot search had a fragment ion mass tolerance of $0.60 \mathrm{Da}$ and a parent ion tolerance of 15 parts per million. Sequest search had a fragment ion mass tolerance of $1.00 \mathrm{Da}$ and a parent ion tolerance of 0.010 Da. Deamidation of asparagine, oxidation of methionine, and iodoacetamide derivative of cysteine were specified in Mascot and Sequest as variable modifications.

Criteria for protein identification. Scaffold (version Scaffold 2_05_02; Proteome Software Inc., Portland, OR, U.S.A.) was used to validate $\mathrm{MS} / \mathrm{MS}$-based peptide and protein identifications. Peptide identifications were accepted if they could be established at greater than $95.0 \%$ probability, as specified by the Peptide Prophet algorithm. Protein identifications were accepted if they could be established at greater than $95.0 \%$ probability, assigned by the Protein Prophet algorithm, and contained at least two identified peptides. Proteins that contained similar peptides and could not be differentiated based on MS/MS analysis alone were grouped to satisfy the principles of parsimony.
Plasmid construction and yeast two-hybrid assay.

Primers were designed to amplify specific regions of genes, with overhanging sequences (attB forward primer: GGGGACAAGTTTGTACAAAAAAGCAGGCT and attB reverse primer: GGGGACCACTTTGTACAAGAAAGCTGGGT) to clone PCR products into Gateway pDONR 207 vector (Invitrogen, Carlsbad, CA, U.S.A.). Amplified regions included the ankyrin domain of ACD6 (ACD6 1-433), putative kinase domains of various RLKs (RGFR1/RGI1 749-1141, RKI3 637-876, FLS2 832-1173, CRK13 323-673, and CRK29 545-876), and three of the predicted intracellular domains of MSL4 (MSL4 5-238, MSL4 397-642, MSL4 707-881). The Gatewaycompatible vectors pLAW10 and pLAW11 used in the yeast two-hybrid experiments were gifts from R. Michelmore. The GAL4 Y2-H system (Clontech Matchmaker System 3, Clontech) was used for the yeast two-hybrid interaction tests. The pLAW10 or pLAW11 vector was transformed into YM187 or AH109 by using the FROZEN-EZ Yeast Transformation II kit (Zymo Research, Irvine, CA, U.S.A.). The plates were then replica-plated onto media with increasing stringency of selection: synthetic defined (SD) medium lacking TRP and LEU (SD-TRP-LEU) and SD medium lacking TRP, LEU and HIS (SD-TRP-LEU-HIS). The plates were incubated at $30^{\circ} \mathrm{C}$ for three to five days for yeast growth. For each assay, two independent sequence-verified clones were used, which gave similar results.

\section{RNA preparation and cDNA synthesis.}

Total RNA preparations were carried out from $0.5 \mathrm{~g}$ of leaf tissue, using Trizol Reagent (Invitrogen), and cDNA synthesis was carried out using Prime Masterscript (Takara, Kusatsu, Japan) according to manufacturer protocols. For RGFR1/RGI1, total RNA was isolated as described above, was supplemented with DNA digestion (New England Biolabs RNase-Free DNase I, Ipswich, MA, U.S.A.), and cDNA synthesis was with the SuperScript III reverse transcription (RT) and Oligo $(\mathrm{dT})_{20}$ primer (Invitrogen), according to the manufacturer's instructions.

\section{RT-PCR and quantitative real-time PCR analyses.}

RT-PCR to verify mutants was performed using the respective gene-specific primers listed in Supplementary Table S5 (25 cycles for all CSPS except RGFRI/RGII, 40 cycles for $R G F R 1 / R G I 1)$ or primers for ACT2 (Tateda et al. 2011) as control. SYBR green master (ROX) (Roche) reagent and Applied Biosystem 7900HT Fast Real-Time PCR system was used for quantitative real time PCR as described (Tateda et al. 2011). For the RGFR1/RGII expression, quantitative real-time PCR was performed as described (Jiang et al. 2015; Mei et al. 2014; Shang et al. 2010), according to the instructions provided for the Bio-Rad Real-Time System CFX96TM C1000 thermal cycler (Bio-Rad). The amount of cDNA was calculated relative to the signal of a standard dilution of the respective PCR products, using SDS2.3 software (Applied Biosystems, Foster City, CA, U.S.A.). Transcript levels of genes relative to $C B P 20$ (Tateda et al. 2011) were determined by real time PCR in Col, acd6-1, and various double mutants.

\section{Callose and cell-death quantitation.}

Callose deposits were stained with aniline blue as described (Kim and Mackey 2008), except chlorophyll was cleared using methanol and acetone (3:1). At least 20 random fields were photographed from leaves of at least 10 independent plants for each genotype (Fig. 6E). To induce callose as shown in Figure 3, leaves were infiltrated with a blunt 1-ml syringe with peptides $(1 \mu \mathrm{M}$ flg22 or $1 \mu \mathrm{M}$ elf18) from Biomatik corporation, $10 \mu \mathrm{g} / \mathrm{ml}$ chitin (C9752; Sigma) or $100 \mu \mathrm{M}$ BTH from R. Dietrich (Syngenta, Greensboro, NC, U.S.A.). Leaves were collected $24 \mathrm{~h}$ after BTH or chitin treatment or $18 \mathrm{~h}$ after flg22 
or elf18 treatment. At least eight random fields were photographed from two leaves of at least three independent plants. Callose quantified by manually counting deposits is presented as a percentage of deposits in Col or acd6-1. Cell-death area was quantified with ImageJ from at least 15 bright-field photographs of leaves stained for callose and was presented as percentage of cell death in acd6-1. Dead cells appeared brown in cleared leaves (callose deposition sites did not correlate with cell-death regions).

\section{Measurement of SA content.}

SA was extracted from six replicates per genotype and was analyzed by HPLC, as previously described (Greenberg et al. 2000; Seskar et al. 1998). Data were corrected for recovery, using samples spiked with $o$-anisic acid as an internal control. SA and $o$-anisic acid content was determined by fluorescence (SA, excitation $301 \mathrm{~nm}$, emission $412 \mathrm{~nm} ; o$-anisic acid, excitation $301 \mathrm{~nm}$, emission $365 \mathrm{~nm}$ ) after separation on a C18 reverse-phase HPLC column (ZORBAX SB-C18; Agilent Technologies, Santa Clara, CA, U.S.A.) with the Agilent Technologies 1200/1100 series LC system. The column was maintained at $25^{\circ} \mathrm{C}$, and methanol and $0.5 \%$ glacial acetic acid $(60: 40, \mathrm{vol} / \mathrm{vol})$ was flowed through with a rate of $1.25 \mathrm{ml} \mathrm{min}^{-1}$ for about $18 \mathrm{~min}$.

\section{Pseudomonas syringae infections.}

Plants were spray-inoculated with Pseudomonas syringae pv. maculicola ES4326 $\mathrm{hrcC}^{-}$at an optical density at $600 \mathrm{~nm}$ of 0.03 and were sampled 3 or 4 days postinoculation to determine the level of colonization, as previously described (Jelenska et al. 2010). Briefly, plants were covered overnight prior to spraying. Freshly grown bacteria from a plate (streaked from a freezer stock) were used to prepare the inoculum. Plants sprayed until the leaves were visibly wet were covered prior to sampling. Eight leaves were sampled for each plant genotype.

\section{ROS accumulation measurements.}

To detect ROS, leaf discs from 19- to 21-day-old plants were floated on water for $4 \mathrm{~h}$ on 96-well plates, as described (Tateda et al. 2014). Total ROS was measured, after adding luminol solution $(34 \mu \mathrm{g}$ of luminol per milliliter, $20 \mu \mathrm{g}$ of peroxidase per milliliter, and either water or $1 \mu \mathrm{M}$ flg22), with a microplate reader (Tecan Safire2; Tecan Group Ltd., Männedorf, Switzerland), as described (Schwessinger et al. 2011), for $30 \mathrm{~min}$.

\section{Statistical analysis.}

Statistical analyses of bacterial colonization data were done using Statview (SAS Institute Inc., Cary, NC, U.S.A.). All other statistical analyses were done using PRISM (GraphPad Software, Inc. La Jolla, CA, U.S.A.).

\section{ACKNOWLEDGMENTS}

National Institutes of Health (R01 GM54292) and National Science Foundation (IOS 1456904) grants supported this work. C. Tateda and S.-C. Jiang were supported by a Japan Society for the Promotion of Science postdoctoral fellowship for Research Abroad and the International Postdoctoral Exchange Fellowship Program 2015 by the Office of China Postdoctoral Council, respectively. D. J. Speed was supported by T32 GM007183. We thank the Ohio State Stock Center for seeds. We thank high school student V. Agrawal of the Illinois Math and Science Academy for help with SA measurements.

\section{LITERATURE CITED}

Acharya, B. R., Raina, S., Maqbool, S. B., Jagadeeswaran, G., Mosher, S. L., Appel, H. M., Schultz, J. C., Klessig, D. F., and Raina, R. 2007. Overexpression of CRK13, an Arabidopsis cysteine-rich receptor-like kinase, results in enhanced resistance to Pseudomonas syringae. Plant J. 50:488-499.
Alfano, J. R., and Collmer, A. 1997. The type III (Hrp) secretion pathway of plant pathogenic bacteria: trafficking harpins, Avr proteins, and death. J. Bacteriol. 179:5655-5662.

Alonso, J. M., Stepanova, A. N., Leisse, T. J., Kim, C. J., Chen, H., Shinn, P., Stevenson, D. K., Zimmerman, J., Barajas, P., Cheuk, R., Gadrinab, C., Heller, C., Jeske, A., Koesema, E., Meyers, C. C., Parker, H., Prednis, L., Ansari, Y., Choy, N., Deen, H., Geralt, M., Hazari, N., Hom, E., Karnes, M. Mulholland, C., Ndubaku, R., Schmidt, I., Guzman, P., Aguilar-Henonin, L., Schmid, M., Weigel, D., Carter, D. E., Marchand, T., Risseeuw, E., Brogden, D., Zeko, A., Crosby, W. L., Berry, C. C., and Ecker, J. R. 2003. Genomewide insertional mutagenesis of Arabidopsis thaliana. Science 301:653-657.

Araya, T., Miyamoto, M., Wibowo, J., Suzuki, A., Kojima, S., Tsuchiya Y. N., Sawa, S., Fukuda, H., von Wirén, N., and Takahashi, H. 2014 CLE-CLAVATA1 peptide-receptor signaling module regulates the expansion of plant root systems in a nitrogen-dependent manner. Proc. Natl. Acad. Sci. U.S.A. 111:2029-2034.

Beckers, G. J., Jaskiewicz, M., Liu, Y., Underwood, W. R., He, S. Y., Zhang, S., and Conrath, U. 2009. Mitogen-activated protein kinases 3 and 6 are required for full priming of stress responses in Arabidopsis thaliana. Plant Cell 21:944-953.

Belkhadir, Y., Jaillais, Y., Epple, P., Balsemão-Pires, E., Dangl, J. L., and Chory, J. 2012. Brassinosteroids modulate the efficiency of plant immune responses to microbe-associated molecular patterns. Proc. Natl. Acad. Sci. U.S.A. 109:297-302.

Boller, T., and Felix, G. 2009. A renaissance of elicitors: Perception of microbe-associated molecular patterns and danger signals by patternrecognition receptors. Annu. Rev. Plant Biol. 60:379-406.

Butt, A., Mousley, C., Morris, K., Beynon, J., Can, C., Holub, E., Greenberg, J. T., and Buchanan-Wollaston, V. 1998. Differential expression of a senescence-enhanced metallothionein gene in Arabidopsis in response to isolates of Peronospora parasitica and Pseudomonas syringae. Plant J. 16: 209-221.

Cao, Y., Liang, Y., Tanaka, K., Nguyen, C. T., Jedrzejczak, R. P., Joachimiak, A., and Stacey, G. 2014. The kinase LYK5 is a major chitin receptor in Arabidopsis and forms a chitin-induced complex with related kinase CERK1. eLife 3:e03766.

Chinchilla, D., Bauer, Z., Regenass, M., Boller, T., and Felix, G. 2006. The Arabidopsis receptor kinase FLS2 binds flg22 and determines the specificity of flagellin perception. Plant Cell 18:465-476.

Chinchilla, D., Zipfel, C., Robatzek, S., Kemmerling, B., Nürnberger, T., Jones, J. D., Felix, G., and Boller, T. 2007. A flagellin-induced complex of the receptor FLS2 and BAK1 initiates plant defence. Nature 448:497-500.

Couto, D., and Zipfel, C. 2016. Regulation of pattern recognition receptor signalling in plants. Nat. Rev. Immunol. 16:537-552.

Danna, C. H., Millet, Y. A., Koller, T., Han, S. W., Bent, A. F., Ronald, P. C., and Ausubel, F. M. 2011. The Arabidopsis flagellin receptor FLS2 mediates the perception of Xanthomonas Ax21 secreted peptides. Proc. Natl. Acad. Sci. U.S.A. 108:9286-9291.

Frei dit Frey, N., Garcia, A. V., Bigeard, J., Zaag, R., Bueso, E., Garmier, M., Pateyron, S., de Tauzia-Moreau, M. L, Brunaud, V., Balzergue, S., Colcombet, J., Aubourg, S., Martin-Magniette, M. L., and Hirt, H. 2014 Functional analysis of Arabidopsis immune-related MAPKs uncovers a role for MPK3 as negative regulator of inducible defences. Genome Biol. 15:R87.

Frei dit Frey, N., Mbengue, M., Kwaaitaalm M., Nitsch, L., Altenbach, D., Häweker, H., Lozano-Duran, R., Njo, M. F., Beeckman, T., Huettel, B., Borst, J. W., Panstruga, R., and Robatzek, S. 2012. Plasma membrane calcium ATPases are important components of receptor-mediated signaling in plant immune responses and development. Plant Physiol. 159:798-809.

Gimenez-Ibanez, S., Hann, D. R., Ntoukakis, V., Petutschnig, E., Lipka, V., and Rathjen, J. P. 2009. AvrPtoB targets the LysM receptor kinase CERK1 to promote bacterial virulence on plants. Curr. Biol. 19:423-429.

Gómez-Gómez, L., and Boller, T. 2000. FLS2: An LRR receptor-like kinase involved in the perception of the bacterial elicitor flagellin in Arabidopsis. Mol. Cell 5:1003-1011.

Greenberg, J. T., Guo, A., Klessig, D. F., and Ausubel, F. M. 1994 Programmed cell death in plants: A pathogen-triggered response activated coordinately with multiple defense functions. Cell 77:551-563.

Greenberg, J. T., Silverman, F. P., and Liang, H. 2000. Uncoupling salicylic acid-dependent cell death and defense-related responses from disease resistance in the Arabidopsis mutant acd5. Genetics 156:341-350.

Hachez, C., Ohashi-Ito, K., Dong, J., and Bergmann, D. C. 2011 Differentiation of Arabidopsis guard cells: Analysis of the networks incorporating the basic helix-loop-helix transcription factor, FAMA. Plant Physiol. 155:1458-1472.

Haswell, E. S., Peyronnet, R., Barbier-Brygoo, H., Meyerowitz, E. M., and Frachisse, J. M. 2008. Two MscS homologs provide mechanosensitive channel activities in the Arabidopsis root. Curr. Biol. 18:730-734. 
He, P., Shan, L., Lin, N. C., Martin, G. B., Kemmerling, B., Nürnberger, T., and Sheen, J. 2006. Specific bacterial suppressors of MAMP signaling upstream of MAPKKK in Arabidopsis innate immunity. Cell 125: 563-575.

Heese, A., Hann, D. R., Gimenez-Ibanez, S., Jones, A. M., He, K., Li, J., Schroeder, J. I., Peck, S. C., and Rathjen, J. P. 2007. The receptor-like kinase SERK3/BAK1 is a central regulator of innate immunity in plants. Proc. Natl. Acad. Sci. U.S.A. 104:12217-12222.

Hruz, T., Laule, O., Szabo, G., Wessendorp, F., Bleuler, S., Oertle, L., Widmayer, P., Gruissem, W., and Zimmermann, P. 2008. Genevestigator v3: A reference expression database for the meta-analysis of transcriptomes. Adv. Bioinforma. 2008:420747.

Huang, P. Y., Yeh, Y. H., Liu, A. C., Cheng, C. P., and Zimmerli, L. 2014. The Arabidopsis LecRK-VI.2 associates with the pattern-recognition receptor FLS2 and primes Nicotiana benthamiana pattern-triggered immunity. Plant J. 79:243-255.

Jelenska, J., van Hal, J. A., and Greenberg, J. T. 2010. Pseudomonas syringae hijacks plant stress chaperone machinery for virulence. Proc. Natl. Acad. Sci. U.S.A. 107:13177-13182.

Jiang, S. C., Mei, C., Liang, S., Yu, Y. T., Lu, K., Wu, Z., Wang, X. F., and Zhang, D. P. 2015. Crucial roles of the pentatricopeptide repeat protein SOAR1 in Arabidopsis response to drought, salt and cold stresses. Plant Mol. Biol. 88:369-385.

Kim, M. G., and Mackey, D. 2008. Measuring cell-wall-based defenses and their effect on bacterial growth in Arabidopsis. Methods Mol. Biol. 415: 443-452.

Kohler, A., Schwindling, S., and Conrath, U. 2002. Benzothiadiazoleinduced priming for potentiated responses to pathogen infection, wounding, and infiltration of water into leaves requires the NPR1/NIM1 gene in Arabidopsis. Plant Physiol. 128:1046-1056.

Krol, E., Mentzel, T., Chinchilla, D., Boller, T., Felix, G., Kemmerling, B., Postel, S., Arents, M., Jeworutzki, E., Al-Rasheid, K. A., Becker, D., and Hedrich, R. 2010. Perception of the Arabidopsis danger signal peptide 1 involves the pattern recognition receptor AtPEPR1 and its close homologue AtPEPR2. J. Biol. Chem. 285:13471-13479.

Lu, H., Liu, Y., and Greenberg, J. T. 2005. Structure-function analysis of the plasma membrane- localized Arabidopsis defense component ACD6. Plant J. 44:798-809.

Lu, H., Rate, D. N., Song, J. T., and Greenberg, J. T. 2003. ACD6, a novel ankyrin protein, is a regulator and an effector of salicylic acid signaling in the Arabidopsis defense response. Plant Cell 15:2408-2420.

Lu, H., Salimian, S., Gamelin, E., Wang, G., Fedorowski, J., LaCourse, W., and Greenberg, J. T. 2009. Genetic analysis of acd6-1 reveals complex defense networks and leads to identification of novel defense genes in Arabidopsis. Plant J. 58:401-412.

Ma, Y., Walker, R. K., Zhao, Y., and Berkowitz, G.A. 2012. Linking ligand perception by PEPR pattern recognition receptors to cytosolic $\mathrm{Ca}^{2+}$ elevation and downstream immune signaling in plants. Proc. Natl. Acad. Sci. U.S.A. 109:19852-19857.

Mei, C., Jiang, S. C., Lu, Y. F., Wu, F. Q., Yu, Y. T., Liang, S., Feng, X. J., Portoles Comeras, S., Lu, K., Wu, Z., Wang, X. F., and Zhang, D. P. 2014. Arabidopsis pentatricopeptide repeat protein SOAR1 plays a critical role in abscisic acid signalling. J. Exp. Bot. 65:5317-5330.

Mishina, T. E., and Zeier, J. 2007. Pathogen-associated molecular pattern recognition rather than development of tissue necrosis contributes to bacterial induction of systemic acquired resistance in Arabidopsis. Plant J. 50:500-513.

Miya, A., Albert, P., Shinya, T., Desaki, Y., Ichimura, K., Shirasu, K., Narusaka, Y., Kawakami, N., Kaku, H., and Shibuya, N. 2007. CERK1, a LysM receptor kinase, is essential for chitin elicitor signaling in Arabidopsis. Proc. Natl. Acad. Sci. U.S.A. 104:19613-19618.

Mosavi, L. K., Cammett, T. J., Desrosiers, D. C., and Peng, Z. Y. 2004. The ankyrin repeat as molecular architecture for protein recognition. Protein Sci. 13:1435-1448.

Ng, G., Seabolt, S., Zhang, C., Salimian, S., Watkins, T. A., and Lu, H. 2011. Genetic dissection of salicylic acid-mediated defense signaling networks in Arabidopsis. Genetics 189:851-859.

Ou, Y., Lu, X., Zi, Q., Xun, Q., Zhang, J., Wu, Y., Shi, H., Wei, Z., Zhao, B., Zhang, X., He, K., Gou, X., Li, C., and Li, J. 2016. RGF1 INSENSITIVE 1 to 5, a group of LRR receptor-like kinases, are essential for the perception of root meristem growth factor 1 in Arabidopsis thaliana. Cell Res. 26:686-698.

Petutschnig, E. K., Jones, A. M., Serazetdinova, L., Lipka, U., and Lipka, V. 2010. The lysin motif receptor-like kinase (LysM-RLK) CERK1 is a major chitin-binding protein in Arabidopsis thaliana and subject to chitin-induced phosphorylation. J. Biol. Chem. 285:28902-28911.

Rate, D. N., Cuenca, J. V., Bowman, G. R., Guttman, D. S., and Greenberg, J. T. 1999. The gain-of-function Arabidopsis acd6 mutant reveals novel regulation and function of the salicylic acid signaling pathway in controlling cell death, defenses, and cell growth. Plant Cell 11:1695-1708.
Ross, A., Yamada, K., Hiruma, K., Yamashita-Yamada, M., Lu, X., Takano, Y., Tsuda, K., and Saijo, Y. 2014. The Arabidopsis PEPR pathway couples local and systemic plant immunity. EMBO J. 33:62-75

Schwessinger, B., Roux, M., Kadota, Y., Ntoukakis, V., Sklenar, J., Jones, A., and Zipfel, C. 2011. Phosphorylation-dependent differential regulation of plant growth, cell death, and innate immunity by the regulatory receptor-like kinase BAK1. PLoS Genet. 7:e1002046.

Seskar, M., Shulaev, V., and Raskin, I. 1998. Endogenous methyl salicylate in pathogen-inoculated tobacco plants. Plant Physiol. 116:387-392.

Shan, L., He, P., Li, J., Heese, A., Peck, S. C., Nürnberger, T., Martin, G. B., and Sheen, J. 2008. Bacterial effectors target the common signaling partner BAK1 to disrupt multiple MAMP receptor-signaling complexes and impede plant immunity. Cell Host Microbe 4:17-27.

Shang, Y., Yan, L., Liu, Z. Q., Cao, Z., Mei, C., Xin, Q., Wu, F. Q., Wang, X. F., Du, S. Y., Jiang, T., Zhang, X. F., Zhao, R., Sun, H. L., Liu, R., Yu, Y. T., and Zhang, D. P. 2010. The Mg-chelatase H subunit of Arabidopsis antagonizes a group of WRKY transcription repressors to relieve ABAresponsive genes of inhibition. Plant Cell 22:1909-1935.

Shinohara, H., Mori, A., Yasue, N., Sumida, K., and Matsubayashi, Y. 2016. Identification of three LRR-RKs involved in perception of root meristem growth factor in Arabidopsis. Proc. Natl. Acad. Sci. U.S.A. 113:3897-3902

Shiu, S. H., Karlowski, W. M., Pan, R., Tzeng, Y. H., Mayer, K. F., and Li, W. H. 2004. Comparative analysis of the receptor-like kinase family in Arabidopsis and rice. Plant Cell 16:1220-1234.

Singh, P., Kuo, Y. C., Mishra, S., Tsai, C. H., Chien, C. C., Chen, C. W., Desclos-Theveniau, M., Chu, P. W., Schulze, B., Chinchilla, D., Boller, T., and Zimmerli, L. 2012. The lectin receptor kinase-VI.2 is required for priming and positively regulates Arabidopsis pattern-triggered immunity. Plant Cell 24:1256-1270.

Song, J. T., Lu, H., McDowell, J. M., and Greenberg, J. T. 2004. A key role for ALD1 in activation of local and systemic defenses in Arabidopsis. Plant J. 40:200-212.

Tanz, S. K., Castleden, I., Hooper, C. M., Vacher, M., Small, I., and Millar, H. A. 2013. SUBA3: A database for integrating experimentation and prediction to define the SUBcellular location of proteins in Arabidopsis. Nucleic Acids Res. 41:D1185-D1191.

Tateda, C., Watanabe, K., Kusano, T., and Takahashi, Y. 2011. Molecular and genetic characterization of the gene family encoding the voltagedependent anion channel in Arabidopsis. J. Exp. Bot. 62:4773-4785.

Tateda, C., Zhang, Z., and Greenberg, J. T. 2015. Linking pattern recognition and salicylic acid responses in Arabidopsis through ACCELERATED CELL DEATH6 and receptors. Plant Signal. Behav. 10:e1010912.

Tateda, C., Zhang, Z., Shrestha, J., Jelenska, J., Chinchilla, D., and Greenberg, J. T. 2014. Salicylic acid regulates Arabidopsis microbial pattern receptor kinase levels and signaling. Plant Cell 26:4171-4187.

Todesco, M., Balasubramanian, S., Hu, T. T., Traw, M. B., Horton, M., Epple, P., Kuhns, C., Sureshkumar, S., Schwartz, C., Lanz, C., Laitinen, R. A., Huang, Y., Chory, J., Lipka, V., Borevitz, J. O., Dangl, J. L., Bergelson, J., Nordborg, M., and Weigel, D. 2010. Natural allelic variation underlying a major fitness trade-off in Arabidopsis thaliana. Nature 465:632-636.

Tsuda, K., Sato, M., Glazebrook, J., Cohen, J. D., and Katagiri, F. 2008. Interplay between MAMP-triggered and SA-mediated defense responses. Plant J. 53:763-775.

Vanacker, H., Lu, H., Rate, D. N., and Greenberg, J. T. 2001. A role for salicylic acid and NPR1 in regulating cell growth in Arabidopsis. Plant J. 28:209-216.

Wang, G. F., Seabolt, S., Hamdoun, S., Ng, G., Park, J., and Lu, H. 2011. Multiple roles of WIN3 in regulating disease resistance, cell death, and flowering time in Arabidopsis. Plant Physiol. 156:1508-1519.

Wang, H., Ngwenyama, N., Liu, Y., Walker, J. C., and Zhang, S. 2007. Stomatal development and patterning are regulated by environmentally responsive mitogen-activated protein kinases in Arabidopsis. Plant Cell 19:63-73.

Willmann, R., Lajunen, H. M., Erbs, G., Newman, M. A., Kolb, D., Tsuda, K., Katagiri, F., Fliegmann, J., Bono, J. J., Cullimore, J. V., Jehle, A. K., Götz, F., Kulik, A., Molinaro, A., Lipka, V., Gust, A. A., and Nürnberger, T. 2011. Arabidopsis lysin-motif proteins LYM1 LYM3 CERK1 mediate bacterial peptidoglycan sensing and immunity to bacterial infection. Proc. Natl. Acad. Sci. U.S.A. 108:19824-19829.

Xu, J., Xie, J., Yan, C., Zou, X., Ren, D., and Zhang, S. 2014. A chemical genetic approach demonstrates that MPK3/MPK6 activation and NADPH oxidase-mediated oxidative burst are two independent signaling events in plant immunity. Plant J. 77:222-234.

Yamaguchi, Y., Huffaker, A., Bryan, A. C., Tax, F. E., and Ryan, C. A. 2010. PEPR2 is a second receptor for the Pep1 and Pep2 peptides and contributes to defense responses in Arabidopsis. Plant Cell 22:508-522.

Yeh, Y. H., Chang, Y. H., Huang, P. Y., Huang, J. B., and Zimmerli, L. 2015. Enhanced Arabidopsis pattern-triggered immunity by overexpression of cysteine-rich receptor-like kinases. Front. Plant Sci. 6:322. 
Zhang, J., Zhang, X., Wang, R., and Li, W. 2014. The plasma membranelocalised $\mathrm{Ca}(2+)$-ATPase ACA8 plays a role in sucrose signalling involved in early seedling development in Arabidopsis. Plant Cell Rep. 33:755-766.

Zhang, Z., Shrestha, J., Tateda, C., and Greenberg, J. T. 2014. Salicylic acid signaling controls the maturation and localization of the arabidopsis defense protein ACCELERATED CELL DEATH6. Mol. Plant 7:1365-1383.

Zipfel, C., Kunze, G., Chinchilla, D., Caniard, A., Jones, J. D., Boller, T., and Felix, G. 2006. Perception of the bacterial PAMP EF-Tu by the receptor EFR restricts Agrobacterium-mediated transformation. Cell 125:749-760.
Zipfel, C., Robatzek, S., Navarro, L., Oakeley, E. J., Jones, J. D., Felix, G., and Boller, T. 2004. Bacterial disease resistance in Arabidopsis through flagellin perception. Nature 428:764-767.

\section{AUTHOR-RECOMMENDED INTERNET RESOURCES}

Genevestigator website: https://genevestigator.com

SUBA3, the subcellular localization database for Arabidopsis proteins: http://suba3.plantenergy.uwa.edu.au 